\title{
HUMAN RESOURCES PERSPECTIVES IN RESOURCING MEDICAL DOCTORS FOR RURAL AREAS
}

\author{
Rossilah Jamil \\ ${ }^{1}$ Associate Professor Dr.Azman Hashim International Business School, University Technology Malaysia, Jalan Sultan \\ Yahya Petra, 54100, Kuala Lumpur Phone No.: + 603-32585108 E-mail address: rosillah@utm.my
}

Received 3108 2021; Accepted 13102021

\begin{abstract}
Scarcity of doctors in rural areas is a global concern. There is a need to understand the underlying reasons from the lense of human resource management that deals with the whole process from employee resourcing to retention. A study was conducted to explore the pull and push factors that explain how medical doctors decide whether or not to serve in rural areas. The study employed focus groups and interviews with medical doctors in Malaysia. The findings revealed the relevance of several factors that influenced rural posting decision. Recommendations are provided on strategies to attract and retain doctors in rural areas.
\end{abstract}

Keywords: attraction, intervention, medical doctors, retention, rural posting, strategy.

JEL Codes: O15, L20.

\section{Introduction}

Global disparities between urban and rural healthcare is a well-acknowledged problem (Scheil-Adlung, 2015). The World Health Organization (WHO) defines health disparities as distribution differences in health resources between different population groups based on their social conditions, including geographical backgrounds. Comparatively, rural residents have lower access to health infrastructures, expertise and information (Chen, et al, 2019). Unsatisfactory healthcare provision deprives rural populations from their fundamental rights to health and well-being. One of the key reasons for the disparity is due to shortage of willing workforce in rural areas (Weinhold and Gurtner, 2014; Douthit, et al, 2015). Despite putting efforts to attract and retain doctors in rural areas, the issue remains a challenge in many countries. In order to attract and keep the best talents, organizations need to be viewed as an attractive workplace, and focus on effective human resource strategies.
Past studies (such as Goma, et al., 2014; Cosgrave, et al., 2015; Durey et al. 2015; Araújo and Maeda, 2013) have shed some lights regarding the drawbacks of rural posting. However, they have been poorlylinked to important theories and concepts in people management that are critical to explain desired work behaviors. Furthermore, people resourcing in public healthcare is unique. Unlike typical organizations that commonly have full autonomy in employee selection, the supply and demand of healthcare workforce is intertwined with public policies, regulations, and national agenda. This makes it harder to control the selection and management of medical doctors for rural posting. Individual factors are nevertheless crucial, and the design of people strategies must appreciate personal backgrounds and preferences. Therefore, exploration of the push and pull factors for rural posting must be studied alongside relevant human resource perspectives so that better interventions can be implemented to address shortage of doctors in rural areas (Godwin, et al. 2014).

Copyright (C 2021 Author(s), published by Vytautas Magnus University. This is an open access article distributed under the terms of the Creative Commons Attribution Non-Commercial 4.0 (CC BY-NC 4.0) license, which permits unrestricted use, distribution, and reproduction in any medium provided the original author and source are credited. The material cannot be used for commercial purposes. 
Against this backdrop, a study was conducted to a study was conducted to explore the pull and push factors that explain how medical doctors decide whether or not to serve in rural areas. The study findings would be subsequently used to recommend interventions that may assist in addressing the urban-rural areas disparity of medical talents. This paper is organised as follow: synthesis of the relevant literature, study methodology, thematic analysis of study findings, and finally discussions and conclusion.

\section{Literature Review}

Talented human resources is crucial for organizational performance (Delery and Shaw, 2001). In a typical resourcing process, organisations choose the best candidates by administering relevant selection tools (Dessler, 2020). An emphasis on fit factors ensures the hired persons stay longer with the organizations. The person-environment fit (PE fit) theory suggests that people seek environment that matches their personal needs and characteristics to maintain consistency, control, belonginess, life satisfaction, and fulfilment (Yu, 2013). The P-E fit theory has its origin to Kurt Lewin's work (1951) who argues that behavior is a result of the person and his/her environment. The P-E fit may consist of five dimensions, i.e. personorganization fit, person-job fit, person-co workers fit, person-supervisor fit, and personvocation fit (Oh et al., 2014; Gürlek, 2020). PE fit influences employees' attitudes, therefore should guide employee selection decisions (Barrick and Parks-Leduc, 2019).

The closer one's personality with his/her organization and job, the better match it will be. Personality refers to the thought patterns, feelings and behaviors that is unique to individuals (Tellegen, 1991). The Big Five Personality, one of the most common personality models, describes people in terms of their levels of individualism, emotional stability, conscientiousness, agreeableness, and openess to experience (Barrick and Mount, 1991; Digman, 1990). Personality test is common tool in employee selection to predict candidates' likely behaviors in a job role. The five personality dimensions are shown to influence a myriad of workplace attitudes, behaviours and performance (Wille, et al, 2014).

Understanding employee motivation can help with attraction and retention strategies (Ramlall, 2004). Motivation is the psychological process that drives employees to exert efforts towards a goal to fulfil individual needs (Mitchell, 1982). Motivational theorists generally agree that motivation requires the desire, ability, and objective to act. The most common motivation theories in employee retention are the need theory, equity theory, expectancy theory, and job design model (Ramlall, 2004). These theories highlight the roles of needs, reinforcement, cognition, job characteristics, and feelings to explain employee behaviours towards their atttitudes towards organisations. For instance, the TwoFactor Theory (Herzberg, 2017), one of the influential need theories, believes that humans have hygiene (extrinsic) needs and growth (intrinsic) needs. The former concerns with the basic individual survival which if missing will result dissatisfaction, but if fulfilled will not motivate nor cause satisfaction. Examples of hygiene factors are company policy, job responsibility, reward system, salary, working conditions, hours of work, job security, and interpersonal relations. The latter refers to the work factors, for example recognition, achievement, responsibility, career advancement and work itself. Intrinsic factors act as the motivators that drive people to put efforts to maximize their potentials.

Relocation of doctors in rural area may be connected to several reasons. Previous studies (eg. Araújo \& Maeda, 2013; Blitz, et al. 2015; Belaid, et al, 2017) have grouped these into personal, work, living condition, career, financial, education, and regulation factors. Personal factors refer to individual characteristics such as gender, family background, age, and personal values. Work factors point to the limitations in rural service that can deter rural posting. Living condition factors include quality of accommodation, transportation, amenities and modern necessities in rural areas. Financial factors refer to direct and indirect monetary incentives 
given with rural posting. Career factors are the opportunities for learning and development. Practising in rural areas can be a very isolated experience that may adversely impact career advancement. Education system deals with the medical curriculum that exposes medical students to rural healthcare such as community-based education and services (Amalba et al, 2020). Mandatory service relates to legislative, administrative, legal or organizational policies to ensure service in rural areas (WHO, 2010).

In order to effectively attract and retain doctors in rural areas, the employment decision factors need to embedded into appropriate strategies (Araújo \& Maeda, 2013; WHO, 2010). Education intervention can include selecting students from rural backgrounds to enroll in medical programmes, establishing medical schools in rural areas, exposing students to rural communities, and matching curriculum with rural health needs. Regulatory intervention encompasses any government control exercised through legislative, administrative, legal, or policy tools (WHO, 2010). It can be in the forms of increased scope and responsibility for doctors to serve in rural areas, dedicated training programmes on rural health, mandatory service in rural areas for a certain period of time, special incentives like scholarship support, loan forgiveness, and rural posting in return to scholarship. Studies show that mandatory service is one the most successful interventions (Matsumoto et al. 2010; Tamang, et al, 2020).

Financial and non-financial incentives consist of providing additional benefits to entice doctors to serve rural areas. Monetary incentives, like a special allowance, are given usually to offset potential loss of extra income for doctors or/and spouses that could have been generated if they stayed in urban areas (Witter et al. 2011; Darkwa et al. 2014). Non-financial incentives, or personal and professional supports, can be in the forms of acceptable living conditions, amenities and infrastructures, safe working condition, adequate workplace facilities, supportive supervision, coaching and mentoring.
Professional isolation is often a problem when serving in rural areas. Regular supervision, coaching and mentoring by specialists or experienced doctors, such as the tele-health programme (Gardiner et al. 2013; WHO, 2010) can ensure that doctors do not feel they have to sacrifice their development by serving in rural areas. Other non-financial practices like continuing education opportunities, fast-track promotion, dedicated professional networks on rural healthcare, recognition of rural healthcare, and coaching can help improving the morale and status of rural doctors (WHO, 2010). Past studies have shown the effectiveness of non-financial incentives in recruiting and retaining medical doctors in rural areas (Alexander \& Fraser, 2007; Gardiner, et al. 2013). These studies show that these interventions can decrease professional isolation and the left-out feeling.

The intervention can also be in the form of personal factors in the sense that rural posting may be assigned to people from certain demographic backgrounds. Studies show the influence of rural upbringing (Quinn et al., 2011), age and career level (Snow et al. 2011), marital status and gender (Dolea et al., 2010). Altruism, religious beliefs, and socio-political convictions also play a role (Araújo \& Maeda, 2013). Effective interventions will not only allow attraction and retention of doctors in rural areas, but also produce favorable impacts on their performance, job satisfaction, and motivation (WHO, 2020; Russell et al, 2017).

In summary, the literature review shows that employee attraction and retention depends on several factors. In a typical profit-oriented organizational setting, these principles are naturally observed by emphasizing the fit factors before accepting new employees. Similarly, organizations will incorporate employees needs and drives in retention strategies. However following these principles are more challenging in public healthcare. Achievement of fit factors may be more difficult because of the resourcing nature of public workforce. National healthcare practices are subject to the WHO standards and guidelines, and are dependent to variables like 
population growth, demographic trends, number of hospitals, fertility rate, and life expectancy. The demand and supply of medical doctors are also interconnected to the country's medical education system, doctor training system, and healthcare regulation bodies. Given this scenario, determining the factors that influence doctors in choosing their posting is important. This paper aims to incorporate the perspectives of human resource management in understanding the push and pull factors for rural posting in order to recommend attraction and retention interventions of doctors in rural areas.

\section{Methodology}

The study was conducted in Malaysia, whose healthcare faces similar challenges with regards to urban-rural healthcare disparity. Its public healthcare is administered by the Ministry of Health. Staff recruitment is centrally managed by the Malaysian Public Service Commission. To become public medical doctors, individuals need to have a medical degree from recognized public or private institutions. A certificate of registration from the Malaysian Medical Council (MMC) is needed to practice. After completing their academic programme, graduates need to apply for a two-year housemanship placement. Prior 2017, they were automatically offered a permanent position and a higher grade promotion after successful completion of housemanship training, Now, with more supply of medical graduates in the market, the employment offer is no longer guaranteed. The study population consisted of public medical doctors. As public doctors, they had undergone job placement application process that required them to choose their posting location (rural vs. urban). Currently, the Ministry imposes a mandatory posting at rural areas for at least one year. Some financial incentives are provided for this purpose.

The study employed focus group discussions and interviews as data collection methods. Three sessions of focus group discussions were conducted on 62 doctors chosen based on the purposive sampling technique. A simple survey questionnaire was administered prior the sessions to capture information on participants' background. The survey also provided a preliminary overview of issues that served as a foundation for further conversation in the discussions. The survey asked the participants to state their gender, place of service, length of service, if they had served in rural areas, if that decision was their own choice or imposed by the Ministry, and their reasons for choosing or not choosing rural areas. A focus group protocol was prepared to loosely guide the discussion process. The protocol states the opening, main, and closing instruction / questions. Examples of questions were: what made doctors chose rural posting, what made them shunned / refused rural posting, what interventions / attractions that the government offered, what did they think about the interventions, and their recommendations to attract and retain doctors in rural areas. Each focus group session lasted about one hour.

The second part of the data collection involved interviewing ten purposively selected doctors who had served in rural areas. An Interview protocol was prepared following a semi-structured interview format and possible themes for analysis were identified. In view of the strengths of 'situated interview questions', the questions may be modified and contextualized according to the backgrounds of interviewees. Example of questions asked were: how did you decide to serve in rural areas, how would you describe your experience serving in the rural areas, what was your view regarding the present practices / supports given to doctors in the rural posting, and how would you recommend (i.e. strategies) to entice doctors to serve in rural areas. The sampling process followed the data saturation principle that was achieved when the study completed its $10^{\text {th }}$ participant. Each interview lasted between one to two hours. The data was transcribed and thematically analyzed using the NVivo software.

\section{Findings. Profiles of Study Participants}

The focus group participants involved 62 medical doctors. Females (40), males (21), and 
no information (1). Majority of them were between 40 to 49 years old (42), followed by 30 to 39 years old (15), and 50 to 59 years old (5). Most had been in the public service for 10 to 19 years (40), $5-9$ years (15), and above 20 years (4). Out of the 62 participants, $38(61 \%)$ stated they had served in rural areas, whereas 24 had no such experience. Those who had the experience mentioned that the rural posting was their own choice (22), whilst 16 stated it was imposed on them.

The interview participants comprised of ten medical doctors (participant $1(\mathrm{P} 1)$ to 10 (P10)) who had undergone rural placement. Out of ten, seven are males and three females. All of them were between 33 to 36 old. They had been serving rural areas from six months (shortest) to four years (longest). Eight participants ( 3 females and 5 males) mentioned that the rural posting were forced on them by the Ministry. The other two (male doctors) stated that the posting location was their choice.

\section{Thematic Analysis}

Data analysis from the focus group discussions and interviews agreed with each other. Several key themes were generated that point to work and career, living condition, education, regulatory, financial, and personal reasons.

\section{Theme - Work and career-related reasons}

Many of the participants were against rural postings because of its work and careerrelated factors. They mentioned that rural clinics significantly lacked basic facilities, manpower, experienced colleagues, and specialist supervision that could help with professional development. They viewed that lack of manpower would translate into high workload involving non-stop on calls and requiring them to be good in all medical areas in order to "run the show" at the clinics. Insufficient medical equipment and workplace facilities were strong push factors against rural posting. Being sent to rural areas without enough facilities was a shock and far from the rosy picture they were presented with during their medical study.

“... we were taught (during medical school) that everything (medical equipment and facilities) would be there. So when you studied, this thing, that thing are there. But when you go there (rural areas).. nothing! When you arrived there, suddenly no equipment... sometimes not because equipment is lacking... (but they are) totally not there... no ultrasound.. sometimes there are facilities but they are faulty.. no maintenance.. not managed properly.. so no point.." $(P 1)$

Rural posting was also perceived lacking the ecosystem for career development. Being in rural areas meant that they would be deprived of opportunities to develop their career and expertise. Some claimed that they were not provided with a training programme prior their rural posting that could have helped them prepare for the awaiting changes and expectations. As a result, they felt professionally and mentally unsupported. Consistent to the earlier findings on workload, the types of clinical procedures performed in rural clinics were considered basic and unhelpful to develop skills and experience. Limitations of clinical procedures and inadequate medical equipment could result a loss of skills due to lack of exposure/practice to cases. Being so far from learning institutions, often located in urban areas, was seen as a disadvantage that could deprive them from opportunities to further study. In other words, rural clinics lacked the ecosystem needed to develop advanced clinical experience as shown by the following quotation:

“... let's say if you want to be a surgeon.. but suddenly.. compulsory for you to go to rural or remote areas.. then cannot practice surgical skills.. this skill you can only get in (urban) hospitals only.. (because) there are consultants there to train you. (but) if you go to rural areas.. for many years.. then (your skills) become rusty... cannot practice.. (there are only basic) 
surgeries in rural areas.. so your skills will be affected..you will lose interests.. then automatically you will not pursue specialist (master program).. if you already set this dream during medical school, then you are posted in rural areas then your dream ruined.." (P7)

Despite acknowledging the lack of facilities and heavy responsibilities as the push factors for rural posting, some participants agreed that all the limitations, imperfections and incompleteness of rural healthcare could also serve as a fertile bed and a knowledge warehouse for development. Rural posting was a stretched assignment that forced them to go out their comfort zone to 'learn more' and 'learn fast'. It was mentioned that those who personally chose rural posting were mainly motivated by these learning opportunities citing reasons such as they 'get to learn more', 'to gain experience', and 'to earn knowledge because the knowledge (or exposure to certain diseases) cannot be acquired in urban posting'. Rural posting had been described as an "eye-opening experience" and a "comprehensive on-the-job training" that required them to know from the basic until complex clinical procedures. The rural posting was viewed as valuable to train doctors to be more independent in handling emergency cases despite limited facilities. The following illustrates these views:

".. If at the remote area, like in a 'orang asli' (indigenous people) village, you are going to acquire like extra field.. you look after their health... their diseases are different from ours (i.e. urban communities). We are going to find disease like... what we read in a book when we studied at university but never saw in reality. Because during housemanship, we were attached at big hospitals so we don't find these textbook diseases... that's why some doctors volunteered to go to rural areas .... for 1, 2, 3 years (because) once you get this extra knowledge, this can help you to become specialists in the future" (P2).

There was a suggestion that some of the drawbacks of rural posting could be minimized if the experience was to appropriately recognized for career development. Currently, it had no weightage in their career progression.
Opportunities for further study were limited and competitive. In order to lessen the lack of training and development in rural areas, one of the participants felt that those with rural posting should be prioritised:

“.. many don't want to go (to rural posting) because they want to stay in their respective department (in big hospital) so easy for them to further study... it's difficult to go back to study (if you are away for some time in rural areas).. now there's age limit to pursue Masters programme. many doctors want to study to be specialists.. but places are limited... if rural posting can be used as a bonus..then it will attract doctors to go to rural areas... then we feel appreciated.. we have sacrificed (by being in rural areas).. then (the Ministry) should make our journey easy to do Master programme.." (P10)

\section{Theme - Living condition reasons}

Rural living condition, including family and lifestyle aspects, was found to be a major push factor. Families was an important factor in posting decision. The participants stated reasons such as spouse reluctance to relocate, spouse employment issue, kids' schooling, parents, marriage relationships, established living arrangements, and other family commitments. If they had to serve rural areas, some doctors would request to be transferred back before their kids started formal schooling. Married doctors would opt for a temporary separate living arrangement from their spouses during their posting. This long distance relationship could put a strain on the marriage, as shared below:

“... rural posting will affect marriage relationship actually... your relationship will be negatively affected.. if you stay there for 2 or 3 years.. then your spouse stay elsewhere... relationship may (emotionally) suffer... they don't have the place to share their feelings, loneliness.. that are important for a healthy relationship..." (P6)

The lack of modern necessities, like infrastructures, entertainment, amenities, transportations, internet connection, and good accommodation, were also mentioned. 
Although the government had provided them with a free accommodation, the quality was felt unacceptable. To an extreme, rural living was likened to a prison:

“...even if you earn a lot of money, you can't spend, you don't know where to spend (because) there's nothing (to spend on)... so can't enjoy... usually... medical practitioners.. we also face stress level. if too stressed, we want to relax... sit at cafes or go to cinemas... So when you are 'chucked away' in rural area you cannot go to these places anymore... when we are there, we are like trapped in one place, like in a prison you know... work only then go home... no life.. very boring.." (P9)

Those who were used to urban lifestyle found it most challenging, in which this pointed to the relevance of one's background:

"... it comes from the background of the family I think... if their background they are not used to this kind of (rural) place, of course, first impression, they won't go". (P5)

On the other hand, some participants found the appeals of rural living. The serenity, slow-paced, quiet life and rural community were reported as the main pull factor for rural posting. Phrases like "ease of life", "slow paced", "less pressure", and "peaceful environment" compared to city life were some of the recurring words mentioned. This more relaxed way of living could benefit them to spend more quality family time. Rural residents were perceived as "nice", "friendly", and "genuin"' (compared to city people). One of the participants reflected and remarked:

"I was really sad and touched when I was finally leaving (finished with the rural posting), so many (local) people came to say goodbye. They gave me things like bananas..corns..etc...not the things (that count) but the thoughts ... gestures.. " (P4)

The study further suggests that some participants had enjoyed their social status in rural areas, not uncommon given the high power distance that typically characterized the Malaysian society.

“... At (my rural posting place), you are safe (because) you are well known. Once you are a doctor in rural area, people will respect you. You want to go every where, people will recognize you. I bring my own car, people will know, that's my car. People won't touch me. People do nothing. Even the police (they said) "eh make way for the doctor (if there's a roadblock)". (P8)

The participants felt that their job as doctors was "more appreciated" and socially respected by patients in rural areas. This was considered an added appeal.

“... Working in rural area at first you feel stressful but (after a while) you will feel very very appreciated.. by the communities who become you patients. the way they appreciate is very different from urban people... urban people will come with information they already googled (about their illness) so when I correct them, they don't want to listen because they think they know better about their illness. they come with the wrong knowledge.. but they don't want to admit because they think they have read (googled) much. In rural area, patients accept whatever the doctor tells them and they are very happy when we advise them, they will listen and follow your advise.." (P2)

Theme - Medical curriculum reasons

The study suggests curriculum inadequacies as a possible push factor. Participants claimed regarding lack of coverage of rural healthcare during their medical programmes. Rural healthcare as a specific course was mainly mentioned by those who attended medical schools outside Malaysia. Some mentioned receiving such exposure only when participating in community programs in rural areas. Lack of exposure could have provided a lopsided impression that healthcare only centralised in big hospitals. The findings also suggests that the curriculum could do more in building the 
characters and professionalism of medical graduates. Some participants made observations regarding the attitudes of young generation of medical doctors:

“.. as a doctor, our aim is to treat people.. so (by right) we don't ... should not let things to prevent us (from doing our responsibility).. so we don't mind (about rural posting), because our aim is only to treat people... but I think nowadays (the situation) changed.. the doctors that we are making now like... they only want to go to work, clock in, clock out and go home... that's it.. they don't care (about work).. even if we set (rural posting) as mandatory they will still not go... because they have this mindset that place is not good.. they don't want to learn..." (P3)

\section{Theme - Compulsory service reasons}

The findings suggests that the participants agreed that the rural compulsory service was good and necessary to enhance healthcare offering to all Malaysians. However, despite the mandatory requirement, the study suggests loopholes in the system. Participants mentioned that there were ways to escape this service, as illustrated below:

“... floating...some doctors will do 'floating' in hospitals. because they already got the posting but they didn't want to go because they don't like the place.. so they will floating at hospital.. they will stay at the emergency department or some other departments... then they appeal.. appeal.. appeal.. appeal.. (to change posting location).. during this time we can find people using cable (i.e. connections) to help them.. yes, it happens.. " $(P 2)$

The Ministry had increased the mandatory service from a minimum of 6 months to 1 year. At the outset, participants felt that the duration was enough to fulfill their obligation. Generally, they did not mind serving for a short period at the beginning of their career and when their children had not started school. There was a practice to state such requests in the posting application form which would be normally fulfilled and respected. Probing further, they however agreed that the duration was a little short to develop quality relationships between doctors and patients needed for healthcare provision.

\section{Theme - Roles of financial allowance}

Finance was also mentioned as one of the factors that played a role in rural posting decision. The allowance currently provided by the government was seen unattractive to entice people to serve in rural areas and incommensurable with the downsides of working in rural areas. However, the study suggests that money was not the deciding factor. The financial allowance only acted as incentives for rural postings, and not as a strong attraction factor. Some terms used to describe the allowance were as "bonus", "consolation", or "relief", to offset some of the shortcomings of working in rural settings. Participants mentioned that they could easily earn extra money if they remained in urban areas by serving as locum doctors, for instance. At the same time, they recognised the lower cost of living in rural areas that may translate to some money saved.

Theme - Rural posting depends on personal factors

The study also found an evidence that whether or not rural posting appealed to the doctors boiled down to the individual personal factors relating to their personality and demography. Some participants perceived rural posting as an opportunity to gain new experience and knowledge, considered it as an "adventure" or a "challenge" that required them to be "open-minded". Participants who perceived their rural experience from positive lenses also seemed to report lesser complaints regarding their posting. To illustrate, one participant shared that he took up jungle trekking to fill his free time, suggesting that he did not face loneliness and boredom, a common complaint regarding rural life. One of the participants came up with a similar observation associating rural posting with individual personality:

“.... (rural posting) is good for people who like nature.. like new things.. like adventure.. experience...not scared of isolated place... is 
like new thing for them to learn. These kind of people... they are more into adventurous.. "(P9)

The study suggests that rural posting was most appealing or relevant to people with certain characteristics, i.e. male, single, without family commitment, and rural upbringing. Personal altruism to serve others also seemed relevant. The general attitude was: "...if you have the passion to serve as a doctor then the place (urban or rural) should not matter...". This view was shared by participants who grew up in rural areas.

“... not many doctors will think that they want to serve rural and remote areas or to return to their (rural) hometown...not many think 'I want to return to my hometown, I want to help my community'. Very very little will think that. (P3)

Those who were brought up in rural areas would be more welcoming to serve in rural communities. Upbringing shapes one's perceptions. Those who grew up in rural areas would be used to rural living conditions. The acceptance towards relative elements like "hygiene", "living standards", "level of comfor", and life with "no electricity, internet, cable $T V$ " for instance varied between those grew up in rural and urban areas. Definition of life necessities for instance also differed as those who grew up in urban areas could consider these as 'necessities' than 'luxuries'. Because of this, there was a general perception that perhaps rural posting was best for ruralborn doctors. Some of the rural areas were also close to their immediate families / parents, therefore, was considered an added attraction in terms of location.

\section{Discussion and Conclusion}

The study was conducted to explore the pull and push factors that may explain how medical doctors decide whether or not to serve in rural areas. Echoing earlier studies, it found the relevance of work and career, rural living condition, education, regulatory, financial, and personal factors in the decision making. Lack of facilities at rural clinics and limitations associated with rural living were considered a major turn off. The importance of family conforms with the socio-cultural characteristics of the country setting whose society often values collectivism, strong family structure, and filial piety (Noordin and Jusoff, 2010; Zawawi, 2008; Hirschman, 2016). Monetary factor was important but not a deciding factor in their selection decision. Perceived lack of exposure towards rural healthcare within medical curriculum could have contributed to the problem. Personal backgrounds of the doctors were also relevant in the decision process.

Based on the Two-Factor Theory, rural work conditions, rural living conditions, and rural allowance can be considered as the basic hygiene factors that need to be provided for rural posting to prevent dissatisfaction. However, providing them may not be enough to motivate or influence decision for rural posting. Whereas, career-related factors can be considered as the growth intrinsic factors. These include pre-rural posting preparatory training programme, learning opportunities, scholarship priority for further study, and mentoring by specialists that can help creating a holistic ecosystem for professional development. Based on Herzberg's, they can be the work motivators to influence doctors to perform, enhance satisfaction and hopefully remain longer at rural posting.

The thematic data analysis represents dual perspectives suggesting how rural experience is based on individual perceptions. One's push factor against rural posting can be another person's pull factor. This points to the importance of one's background. The study suggests that rural posting seems to be more suited and welcoming to doctors with certain socio-demographic characteristics and personality type. Those who were single, male, lacked family commitment, and came from rural background were more positive with their rural experience, hence are consistent with previous studies. Based on the Big Five model, certain personality dimensions such as extraversion and openness to experience 
probably best describe these individuals. Doctors with higher level of these two traits are acknowledgedly better in appreciating, learning, and adjusting to new situations (Guan, et al, 2017; Blickle, 1996). The study suggests that the participants who perceived their rural experience favorably reported less issues or problems with regards to the data themes. In this sense, it relates to the idea of Fit Theory that emphasises on a close match between employees and their work environment to enhance employee retention and positive work attitudes.

Based on the findings, several recommendations can be proposed to improve interventions to attract and retain rural doctors. There should be more emphasis on the right background and personality of doctors to be posted in rural areas. Relevant personality tests can be administered, and those with higher level of openness to experience trait may be more suitable candidates. As the study found, the ecosystem and opportunities for professional development were perceived lacking for rural doctors. Yet, these factors are also the key growth and intrinsic factors that could potentially help in influencing decision to serve in rural areas. Therefore, training and development programmes, supports, and development opportunities for doctors who serve in rural areas should be widened and improved to provide duly recognition to their rural service. The study also highlights rooms for improvements in the aspects of education and mandatory service interventions. Further emphasis on rural healthcare is needed within local medical curriculum. The process involved in managing doctor posting location should also be enhanced.

In conclusion, this paper has provided an added understanding of the push and pull factors for rural posting among medical doctors. The findings confirms the importance of several factors in influencing the doctors' perceptions towards rural posting. Drawing upon relevant human resource theories and concepts, the study points to the link of one's personality and growth factors that need to be embedded into attraction and retention strategies of rural doctors. The recommendations may be beneficial to relevant stakeholders, in the study context and elsewhere, to improve their understanding of the study problem and revisit existing interventions. The study is not without limitation. The sampling coverage is restricted due to its qualitative nature. Future studies may include more participants focusing on doctors who have served beyond the mandatory period, and adopt the phenomenological qualitative approach to appreciate individual accounts and experience.

\section{Acknowledgements}

The study was funded by the Fundamental Research Grant Scheme from the Ministry of Higher Education Malaysia (Ref: FRGS/1/2017/SSO3/UTM/02/5).

\section{References}

Alexander, C., \& Fraser, J. D. (2007). Education, training and support needs of Australian trained doctors and international medical graduates in rural Australia: a case of special needs?. Rural \& Remote Health, 7(2).

Amalba, A., Abantanga, F. A., Scherpbier, A. J., \& Van Mook, W. N. (2020). The Role of Community-Based Education and Service (COBES) in Undergraduate Medical Education in Reducing the Mal-Distribution of Medical Doctors in Rural Areas in Africa: A Systematic Review. Health Professions Education, 6(1), 9-18.

Araujo, E., \& Maeda, A. (2013). How to recruit and retain health workers in rural and remote areas in developing countries: a guidance note. HNP Discussion Paper Series.

Barrick, M. R., \& Mount, M. K. (1991). The big five personality dimensions and job performance: a metaanalysis. Personnel psychology, 44(1), 1-26.

Barrick, M. R., \& Parks-Leduc, L. (2019). Selection for fit. Annual review of organizational psychology and organizational behavior, 6, 171-193.

Belaid, L., Dagenais, C., Moha, M., \& Ridde, V. (2017). Understanding the factors affecting the attraction and retention of health professionals in rural and remote areas: a mixed-method study in Niger. Human resources for health, 15(1), 1-11. 

337-352.

Blickle, G. (1996). Personality traits, learning stratigies, and performance. European Journal of personality, 10(5),

Blitz, J., Coetzee, J. F., Jenkins, L. S., \& Gunst, C. (2015). What keeps health professionals working in rural district hospitals in South Africa?. African Journal of Primary Health Care and Family Medicine, 7(1), 1-7.

Chen, X., Orom, H., Hay, J. L., Waters, E. A., Schofield, E., Li, Y., \& Kiviniemi, M. T. (2019). Differences in rural and urban health information access and use. The Journal of Rural Health, 35(3), 405-417.

Cosgrave, C., Hussain, R., \& Maple, M. (2015). Factors impacting on retention amongst community mental health clinicians working in rural Australia: A literature review. Advances in Mental Health, 13(1), 58-71.

Darkwa, E. K., Newman, M. S., Kawkab, M., \& Chowdhury, M. E. (2015). A qualitative study of factors influencing retention of doctors and nurses at rural healthcare facilities in Bangladesh. BMC health services research, 15(1), 1-12.

Delery, J. E., \& Shaw, J. D. (2001). The strategic management of people in work organizations: Review, synthesis, and extension. Research in personnel and human resources management, 20, 165-197.

Dessler, G. (2020). Human resource management. $16^{\text {th }}$ edition. Pearson.

Digman, J. M. (1990). Personality structure: Emergence of the five-factor model. Annual review of psychology, 4l(1), 417-440.

Dolea, C., Stormont, L., \& Braichet, J. M. (2010). Evaluated strategies to increase attraction and retention of health workers in remote and rural areas. Bulletin of the World Health Organization, 88, 379-385.

Douthit, N., Kiv, S., Dwolatzky, T., \& Biswas, S. (2015). Exposing some important barriers to health care access in the rural USA. Public health, 129(6), 611-620.

Durey, A., Haigh, M., \& Katzenellenbogen, J. M. (2015). What role can the rural pipeline play in the recruitment and retention of rural allied health professionals?. Rural and Remote Health, 15(3438).

Gardiner, M., Kearns, H., \& Tiggemann, M. (2013). Effectiveness of cognitive behavioural coaching in improving the well-being and retention of rural general practitioners. Australian Journal of Rural Health, 21(3), 183-189.

Godwin, D. M., Hoang, H., Crocombe, L. A., \& Bell, E. (2014). Dental practitioner rural work movements: a systematic review. Rural and Remote Health, 14(2825).

Goma, F. M., Murphy, G. T., MacKenzie, A., Libetwa, M., Nzala, S. H., Mbwili-Muleya, C., ... \& Gough, A. (2014). Evaluation of recruitment and retention strategies for health workers in rural Zambia. Human resources for health, 12(1), 1-9.

Guan, Y., Dai, X., Gong, Q., Deng, Y., Hou, Y., Dong, Z., ... \& Lai, X. (2017). Understanding the trait basis of career adaptability: A two-wave mediation analysis among Chinese university students. Journal of Vocational Behavior, 101, 32-42.

Gürlek, M. (2020). The role of acculturation in hotel managers' person-environment (PE) fit and hiring decisions: An experimental study on immigrant job applications. Tourism Management Perspectives, 36, 100739.

Herzberg, F. (2017). Motivation to work. Routledge.

Hirschman, C. (2016). Gender, the status of women, and family structure in Malaysia. Malaysian Journal of Economic Studies, 53(1), 33-50.

Lewin, K. (1951). Intention, will and need. In D. Rapaport, Organization and pathology of thought: Selected sources (pp. 95-153). Columbia University Press.

Matsumoto, M., Inoue, K., \& Kajii, E. (2010). Policy implications of a financial incentive programme to retain a physician workforce in underserved Japanese rural areas. Social science \& medicine, 71(4), 667-671.

Mitchell, T. R. (1982). Motivation: New directions for theory, research, and practice. Academy of management review, $7(1), 80-88$.

Noordin, F., \& Jusoff, K. (2010). Individualism-Collectivism and Job Satisfaction between Malaysia and Australia. International Journal of Educational Management, 24(2), 159-174.

Oh, I. S., Guay, R. P., Kim, K., Harold, C. M., Lee, J. H., Heo, C. G., \& Shin, K. H. (2014). Fit happens globally: A meta-analytic comparison of the relationships of person-environment fit dimensions with work attitudes and performance across East Asia, Europe, and North America. Personnel Psychology, 67(1), 99-152.

Quinn, C. H., Ziervogel, G., Taylor, A., Takama, T., \& Thomalla, F. (2011). Coping with multiple stresses in rural South Africa. Ecology and Society, 16(3).

Ramlall, S. (2004). A review of employee motivation theories and their implications for employee retention within organizations. Journal of American academy of business, 5(1/2), 52-63.

Russell, D. J., McGrail, M. R., \& Humphreys, J. S. (2017). Determinants of rural Australian primary health care worker retention: a synthesis of key evidence and implications for policymaking. Australian Journal of Rural Health, 25(1), 5-14.

Scheil-Adlung, X. (2015). Global evidence on inequities in rural health protection: new data on rural deficits in health coverage for 174 countries. International Labour Organization. 
Snow, R. C., Asabir, K., Mutumba, M., Koomson, E., Gyan, K., Dzodzomenyo, M., ... \& Kwansah, J. (2011). Key factors leading to reduced recruitment and retention of health professionals in remote areas of Ghana: a qualitative study and proposed policy solutions. Human resources for health, 9(1), 1-11.

Tamang, B., Poudel, P. K., Karki, S. J., \& Gautam, R. (2020). A mandatory bonding service program and its effects on the perspectives of young doctors in Nepal. Rural and remote health, 20(1), 5457-5457.

Tellegen, A. (1991). Personality traits: Issues of definition, evidence, and assessment. In D. Cicchetti \& W. M. Grove (Eds.), Thinking clearly about psychology: Essays in honor of Paul E. Meehl, Vol. 1. Matters of public interest; Vol. 2. Personality and psychopathology (pp. 10-35). University of Minnesota Press.

Trevor Yu, K. Y. (2013). A Motivational Model of Person-Environment Fit: Psychological Motives as Drivers of Change. Organizational Fit: Key Issues and New Directions, 19-49.

Weinhold, I., \& Gurtner, S. (2014). Understanding shortages of sufficient health care in rural areas. Health Policy, 118(2), 201-214.

Wille, B., Hofmans, J., Feys, M., \& De Fruyt, F. (2014). Maturation of work attitudes: Correlated change with Big Five personality traits and reciprocal effects over 15 years. Journal of Organizational Behavior, 35(4), 507-529.

Witter, S., Ha, B. T. T., Shengalia, B., \& Vujicic, M. (2011). Understanding the'four directions of travel': qualitative research into the factors affecting recruitment and retention of doctors in rural Vietnam. Human resources for health, 9(1), 1-14.

World Health Organization. (2010). Increasing access to health workers in remote and rural areas through improved retention: global policy recommendations. World Health Organization.

World Health Organization. (2020). Improving retention of health workers in rural and remote areas: Case studies from WHO South-East Asia Region.

Zawawi, D. (2008). Cultural dimensions among Malaysian employees. International journal of economics and management, 2(2), 409-426. 